\title{
ANALISIS PENGARUH MODEL PEMBELAJARAN COURSE REVIEW HORAY (CRH) TERHADAP HASIL BELAJAR SISWA SEKOLAH DASAR
}

\author{
Mirtha Absari ${ }^{1)}$ Deni Adi Putra ${ }^{2)}$ Fitroh Setyo Putro Probowo ${ }^{3)}$ \\ 1),2,3) Program Studi Pendidikan Guru Sekolah Dasar UMSurabaya \\ *Corresponding author E-mail: mirthaabsari@gmail.com
}

\begin{abstract}
Abstrak
Kata Kunci: Model Pembelajaran, Course Review Horay (CRH), Hasil Belajar

Penelitian ini memiliki tujuan untuk menganalisis pengaruh model pembelajaran Course Review Horay $(\mathrm{CRH})$ terhadap hasil belajar siswa sekolah dasar. Hal ini disebabkan karena masih banyak guru yang menggunakan metode pembelajaran yang konvensional sehingga menyebabkan siswa merasa bosan dan jenuh. Agar proses pembelajaran dapat berlangsung dengan baik, guru perlu mempersiapkan skenario pembelajaran dengan cermat dan jelas agar siswa tidak bosan dan jenuh serta mendapatkan hasil belajar yang optimal, salah satunya dengan menggunakan model pembelajaran. Metode yang digunakan dalam penulisan artikel ini adalah metode studi literature jenis kualitatif. Subjek dalam penulisan ini merujuk pada 10 jurnal yang relevan. Hasil analisis tercatat bahwa model pembelajaran Course Review Horay (CRH) memiliki pengaruh terhadap hasil belajar siswa pada tingkat sekolah dasar. Rata-rata yang diperoleh terhadap hasil belajar mencapai 33,4\% dengan kategori yang terendah $11 \%$, tertinggi $65 \%$ dan total ketuntasan hasil belajar rata-rata setelah menerapkan model pembelajaran Course Review Horay (CRH) adalah mencapai 62,65\%. Berdasarkan penelitian ini model pembelajaran Course Review Horay (CRH) dapat digunakan sebagai variasi baru dalam proses belajar mengajar, yaitu pembelajaran yang aktif dan efektif pada siswa sekolah dasar.
\end{abstract}

\section{Abstract}

\begin{abstract}
Keywords: Learning Model, Course Review Horay (CRH), Learning Outcomes

This study aims to analyze the effect of the Course Review Horay (CRH) learning model on learning outcomes of elementary school students. This is because there are still many teachers who use conventional learning methods, causing students to feel bored and bored. In order for the learning process to take place well, teachers need to prepare learning scenarios carefully and clearly so that students don't get bored and bored and get optimal learning outcomes, one of which is by using a learning model. The method used in writing this article is a qualitative literature study method. The subjects in this writing refer to 10 relevant journals. The results of the analysis noted that the Course Review Horay (CRH) learning model has an influence on student learning outcomes at the elementary school level. The average obtained for learning outcomes reached $33.4 \%$ with the lowest category $11 \%$, the highest $65 \%$ and the average total completeness of learning outcomes after implementing the Course Review Horay $(\mathrm{CRH})$ learning model was $62.65 \%$. Based on this research, the Course Review Horay $(\mathrm{CRH})$ learning model can be used as a new variation in the teaching and learning process, namely active and effective learning in elementary school students.
\end{abstract}

\section{Pendahuluan}

Pendidikan merupakan suatu hal yang sangat penting dalam membangun sebuah peradaban bangsa yang dapat berlangsung secara terus menerus sepanjang hayat dan satu-satunya asset untuk membangun sumber daya manusia yang berkualitas (Shoimin, 2014:20). Kualitas pendidikan merupakan salah satu faktor yang 
menentukan kualitas sumber daya manusia suatu bangsa. Berkaitan dengan tuntutan untuk menghasilkan sumber daya manusia yang berkualitas, maka kualitas pendidikan perlu ditingkatkan secara berkesinambungan dan ditingkatkan pada semua mata pelajaran (Dewi, 2014:2). Salah satu langkah untuk mendapatkan kualitas dalam pendidikan adalah dengan cara melaksanakan suatu pembelajaran.

Pembelajaran merupakan suatu istilah yang telah dikenal oleh masyarakat luas, terlebih di dalam dunia pendidikan. Pembelajaran merupakan rangkaian kegiatan yang dilakukan pendidik guna untuk membantu peserta didik agar mereka dapat menerima suatu pengetahuan yang telah diberikan dan membantu mereka untuk memudahkan pencapaian keberhasilan dari suatu pembelajaran (Suprihatiningrum, 2013:75).

Agar proses pembelajaran dapat berlangsung dengan baik, guru perlu mempersiapkan skenario pembelajaran dengan cermat dan jelas. Hal pokok dalam proses pembelajaran yaitu: (1) Interaksi Pembelajaran yang didominasi oleh interaksi antara guru dan siswa, guru akan mempengaruhi siswa dan sebaliknya siswa akan mempengaruhi guru; (2) Proses Pembelajaran dalam Perspektif Siswa, serangkaian upaya untuk mengembangkan kemampuan siswa; (3) Proses Pembelajaran dalam Perspektif Guru, mencakup segala kegiatan menciptakan situasi agar para siswa

Dalam kegiatan pembelajaran, model sangat diperlukan oleh guru. Seorang guru tidak akan dapat mengajar dengan baik apabila tidak belajar secara optimal (Suprihatiningrum, 2013:81).

Dalam pelaksanaan pembelajaran di sekolah, seorang guru harus pandai dalam menciptakan suatu iklim pembelajaran sehingga siswa dapat aktif dalam mengembangkan potensi dirinya, misalnya siswa dapat belajar berinteraksi dengan teman-temannya di dalam kelas serta dapat secara aktif menyelesaikan permasalan-permasalahan yang diberikan oleh guru, Namun sayangnya, dalam proses pembelajaran di SD sering kali muncul suatu permasalahan, yaitu keberhasilan pembelajaran yang kurang optimal (Nureva, 2019:3). Hal ini disebabkan karena masih banyak guru yang menggunakan metode pembelajaran terdahulu, dimana pembelajaran hanya berpusat pada guru (teacher centered) dan siswa hanya dijadikan sebagai objek pembelajaran yang menerima apa yang disampaikan oleh guru (Kusumahati, 2014:2). Hal tersebut membuat siswa cenderung pasif dalam pembelajaran karena siswa hanya mendengarkan ceramah yang diberikan oleh guru. Siswa menunggu sampai guru selesai menjelaskan kemudian mencatat apa yang diberikan oleh guru tanpa memaknai konsepkonsep yang diberikan. Pembelajaran yang demikian tentu akan membuat siswa bosan dan jenuh dalam mengikuti pembelajaran, sehingga berdampak negatif terhadap hasil belajar siswa (Ani,2016:10).

menguasai model secara tepat. Model pembelajaran Course Review Horay ( $\mathrm{CRH}$ ) merupakan salah satu dari sekian banyak model 
yang sering digunakan, karena dengan menggunakan model yang bervariasi khususnya model pembelajaran Course Review Horay (CRH) dalam pembelajaran di sekolah akan memberikan sebuah nuansa baru dalam pembelajaran yang cenderung konvensional (Ramli, 2016:2).

\section{Model pembelajaran Course Review} Horay (CRH) dapat digunakan sebagai variasi baru dalam proses belajar mengajar, yaitu pembelajaran yang aktif dan efektif (Setyaningsih, 2019:8). Model pembelajaran ini menjadikan suasana kelas meriah dan menyenangkan menurut Sani (dalam jurnal Cholifatin, 2018:3), dapat menarik perhatian dan partisipasi siswa karena terdapat yel-yel untuk setiap kali menjawab benar. Kelebihan model pembelajaran ini ialah pembelajaran yang tidak monoton karena terdapat hiburan berupa yel-yel. Siswa menjadi termotivasi dalam menjawab dengan benar, serta melatih kerjasama tim. Hal ini sesuai dengan karekteristik siswa SD yang memiliki karakteristik senang bermain, senang bergerak dan berkelompok. Menurut Huda (dalam jurnal Cholifatin, 2018:3) Course Review Horay $(\mathrm{CRH})$ digunakan untuk mengukur pengetahuan siswa dalam mejawab pertanyaan, dimana siswa atau kelompok yang benar harus meneriakkan hore atau "yel-yel", model pembelajaran ini juga membantu siswa dalam memahami konsep-konsep pada semua mata pelajaran.

Hasil belajar merupakan hasil dari penguasaan ilmu pengetahuan yang telah dicapai oleh peserta didik setelah mereka menyelesaikan materi pelajaran yang kemudian diwujudkan dalam bentuk perubahan tingkahlakunya (Sinar, 2018:20). Untuk mengetahui tujuan hasil belajar yang dikehendaki dapat diketahui melalui evaluasi. Menurut Sunal (dalam buku Susanto, 2013:5), menerangkah bahwa evaluasi merupakan proses penggunaan informasi untuk membuat pertimbangan seberapa efektif suatu program telah memenuhi kebutuhan siswa. Dengan adanya evaluasi ini dapat dijadikan umpan balik untuk mengukur tingkat penugasan siswa.

Menurut Wasliman (dalam buku Susanto, 2013:12) hasil belajar yang telah diraih oleh siswa adalah sebuah hasil perpaduan antara dua faktor yang mempengaruhi, diantaranya adalah faktor internal maupun eksternal. Faktor internal sendiri merupakan faktor yang diperoleh dari dalam diri peserta didik itu sendiri yang dapat mempengaruhi hasil belajarnya. Sedangkan faktor eksternal merupakan faktor yang berasal dari luar diri peserta didik yang dapat mempengaruhi hasil belajarnya. Berdasarkan hasil pada pendahuluan di atas, penulis merumuskan pertanyaan terkait seberapa besar prosentase rata-rata dari hasil belajar peserta didik ketika dalam mengajar guru tidak menggunkan model pembelajaran Course Review Horay (CRH) dan guru menggunakan model pembelajaran tersebut.

\section{Metode Penelitian}

Metode penelitian yang dipergunakan dalam penelitian ini adalah menggunakan 
metode studi literatur. Metode studi literatur merupakan suatu metode dimana peneliti mampu menelaah secara tekun akan kepustakaan yang diperlakukan dalam sebuah penelitian (Sugiyono, 2019:155). Penelitian ini menggunakan data sekunder yang dimana peneliti memperoleh data secara tidak langsung dengan cara menelusuri jurnal-jurnal relevan yang telah tersedia di media elektronik dan buku-buku yang relevan sesuai dengan judul yang penulis ajukan.

Penulis menggunakan Google Scholar sebagai pencarian data jurnal-jurnal yang telah dirujuk oleh penulis sesuai dengan kriteria yang dibutuhkan. Data yang penulis ambil meliputi data terkait hasil belajar serta pengaruh pembelajaran menggunakan model Course Review Horay (CRH) terhadap hasil belajar siswa di jenjang sekolah dasar. Hasil dari beberapa jurnal tersebut selanjutnya akan di analisis menggunakan metode analisis korelasi untuk mengetahui seberapa pengaruhnya hasil belajar peserta didik ketika dalam mengajar guru tidak menggunakan model $(\mathrm{CRH})$ atau sebelum diberikan treatment dan guru menggunakan model pembelajaran $(C R H)$ atau sesudah diberikan treatment.

Analisis pada metode penelitian ini menggunakan metode pembanding yang berguna untuk menentukan data selisih sebelum diberikan treatment dan setelah diberikan treatment. Lalu data yang telah diperoleh dibagi dengan data sebelum diberikan treatment dan setelah itu duhitung skor untuk mengetahui berapa (\%) pengaruh hasil belajar peserta didik.

\section{Hasil Penelitian dan Pembahasan}

Hasil penelitian yang relevan dalam penelitian studi literature ini adalah sebagai berikut:

1. Nur Eva, Siska Wulandari: Pengaruh Model Pembelajaran Course Review Horay (CRH) Terhadap Hasil Belajar Siswa.

2. Ramli, Isnawati: Upaya Meningkatkan Hasil Belajar IPS Dengan Menggunakan Model Pembelajaran Course Review Horay.

3. Meidian Kusumahati: Keefektifan Model Course Review Horay Terhadap Peningkatan Hasil Belajar IPS.

4. Siti Hamdah, Umayah: Pengaruh Model Course Review Horay Terhadap Hasil Belajar IPS Materi Mengenal Perkembangan Teknologi Transportasi.

5. Yulia Ratna Hesti Setyaningsih, Qoriati Mushafanah, Henry Januar Saputra: Pengaruh Model Course Review Horay

6. Untuk Meningkatkan Aktivitas dan Hasil Belajar Siswa Kelas V Sekolah Dasar.

7. G.H. Andika Pratama, Ndara Tanggu Renda, Ketut Pudjawan: Pengaruh Model Pembelajaran $\mathrm{CRH}$ Berbantuan Media Audio Visual Terhadap Hasil Belajar IPS.

8. Nurul Afifah Cholifatin: Meningkatkan Hasil Belajar IPS Dengan Model Course Review Horay Siswa Kelas IV

9. Ni Kadek Ani, Ni Nyoman Garminah, I Kadek Suartama: Pengaruh Model Pembelajaran CRH Berbantuan LKS 
Terhadap Hasil Belajar Matematika Siswa Kelas IV SD

10. Ni Made Marteni Dewi, Desak Putu Parmiti, Putu Nanci Riastini: Pengaruh Model Pembelajaran Kooperatif Tipe Course Review Horay (CRH) Terhadap Hasil Belajar IPA Pada Siswa Kelas V SD Tahun Pelajaran 2013/2014 Di Gugus IV Kecamatan Buleleng.
11. Holisna Midola: Pengaruh Model Pembelajaran Course Review Horay Terhadap Hasil Belajar IPS Siswa Kelas V SDN 15 Sungai Geringging.

Berdasarkan data dan hasil jurnal yang telah dirujuk dalam penelitian ini, maka data yang telah didapatkan diolah kembali dengan merangkum hasil penelitian yang relevan. Selanjutnya data dianalisis secara deskriptif kuantitatif dan kualitatif.

Tabel 1 Hasil Analisis Course Review Horay (CRH) Terhadap Hasil Belajar

\begin{tabular}{|c|c|c|c|c|c|c|c|}
\hline \multirow[t]{2}{*}{ No } & \multirow[t]{2}{*}{ Judul } & \multirow{2}{*}{$\begin{array}{c}\text { Nama } \\
\text { Peneliti }\end{array}$} & \multirow{2}{*}{$\begin{array}{l}\text { Nama } \\
\text { Jurnal }\end{array}$} & \multicolumn{4}{|c|}{ Pengaruh Hasil Belajar } \\
\hline & & & & Sebelum & Setelah & Selisih & $\%$ \\
\hline 1 & $\begin{array}{l}\text { Pengaruh Model } \\
\text { Pembelajaran } \\
\text { Course Review } \\
\text { Horay (CRH) } \\
\text { Terhadap Hasil } \\
\text { Belajar Siswa }\end{array}$ & $\begin{array}{c}\text { Nur Eva, Siska } \\
\text { Wulandari }\end{array}$ & $\begin{array}{l}\text { Jurnal Iqra': } \\
\text { Kajian Ilmu } \\
\text { Pendidikan }\end{array}$ & 57 & 75 & 18 & 31 \\
\hline 2 & $\begin{array}{l}\text { Upaya } \\
\text { Meningkatkan } \\
\text { Hasil Belajar IPS } \\
\text { Dengan } \\
\text { Menggunakan } \\
\text { Model } \\
\text { Pembelajaran } \\
\text { Course Review } \\
\text { Horay }\end{array}$ & Ramli, Isnawati & $\begin{array}{l}\text { Bitnet: Jurnal } \\
\text { Pendidikan } \\
\text { Teknologi } \\
\text { Informasi }\end{array}$ & 45,89 & 74,46 & 28,57 & 62 \\
\hline 3 & $\begin{array}{l}\text { Keefektifan Model } \\
\text { Course Review } \\
\text { Horay Terhadap } \\
\text { Peningkatan Hasil } \\
\text { Belajar IPS }\end{array}$ & $\begin{array}{c}\text { Meidian } \\
\text { Kusumahati }\end{array}$ & $\begin{array}{c}\text { Journal } \\
\text { Elementary } \\
\text { Education }\end{array}$ & 68,55 & 81,25 & 12,7 & 18 \\
\hline 4 & $\begin{array}{l}\text { Pengaruh Model } \\
\text { Course Review } \\
\text { Horay Terhadap } \\
\text { Hasil Belajar IPS } \\
\text { Materi Mengenal } \\
\text { Perkembangan } \\
\text { Teknologi } \\
\text { Transportasi }\end{array}$ & $\begin{array}{l}\text { Siti Hamdah, } \\
\text { Umayah }\end{array}$ & $\begin{array}{l}\text { Primary: Jurnal } \\
\text { Keilmuan dan } \\
\text { Kependidikan } \\
\text { Dasar }\end{array}$ & 67,27 & 79,09 & 11,82 & 17 \\
\hline 5 & $\begin{array}{l}\text { Pengaruh Model } \\
\text { Course Review } \\
\text { Horay Untuk } \\
\text { Meningkatkan } \\
\text { Aktivitas dan Hasil } \\
\text { Belajar Siswa } \\
\text { Kelas V Sekolah } \\
\text { Dasar }\end{array}$ & $\begin{array}{l}\text { Yulia Ratna } \\
\text { Hesti } \\
\text { Setyaningsih, } \\
\text { Qoriati } \\
\text { Mushafanah, } \\
\text { Henry Januar } \\
\text { Saputra }\end{array}$ & $\begin{array}{c}\text { Jurnal Pemikiran } \\
\text { dan } \\
\text { Pengembangan } \\
\text { Sekolah Dasar } \\
\text { (JP2SD) }\end{array}$ & 67 & 81,75 & 14,75 & 22 \\
\hline 6 & $\begin{array}{l}\text { Pengaruh Model } \\
\text { Pembelajaran CRH } \\
\text { Berbantuan Media } \\
\text { Audio Visual } \\
\text { Terhadap Hasil } \\
\text { Belajar IPS }\end{array}$ & $\begin{array}{l}\text { G.H. Andika } \\
\text { Pratama, Ndara } \\
\text { Tanggu Renda, } \\
\text { Ketut Pudjawan }\end{array}$ & $\begin{array}{c}\text { Journal for } \\
\text { Lesson and } \\
\text { Learning Studies }\end{array}$ & 28,51 & 31,8 & 3,29 & 11 \\
\hline 7 & $\begin{array}{l}\text { Meningkatkan } \\
\text { Hasil Belajar IPS } \\
\text { Dengan Model } \\
\text { Course Review } \\
\text { Horay Siswa Kelas } \\
\text { IV }\end{array}$ & $\begin{array}{l}\text { Nurul Afifah } \\
\text { Cholifatin }\end{array}$ & Basic Education & 50,94 & 80,73 & 29,79 & 58 \\
\hline
\end{tabular}




\begin{tabular}{|c|c|c|c|c|c|c|c|}
\hline 8 & $\begin{array}{l}\text { Pengaruh Model } \\
\text { Pembelajaran CRH } \\
\text { Berbantuan LKS } \\
\text { Terhadap Hasil } \\
\text { Belajar } \\
\text { Matematika Siswa } \\
\text { Kelas IV SD }\end{array}$ & $\begin{array}{l}\text { Ni Kadek Ani, } \\
\text { Ni Nyoman } \\
\text { Garminah, I } \\
\text { Kadek Suartama }\end{array}$ & $\begin{array}{c}\text { Jurnal Mimbar } \\
\text { PGSD } \\
\text { Universitas } \\
\text { Pendidikan } \\
\text { Ganesha }\end{array}$ & 11,27 & 18,63 & 7,36 & 65 \\
\hline 9 & $\begin{array}{l}\text { Pengaruh Model } \\
\text { Pembelajaran } \\
\text { Kooperatif Tipe } \\
\text { Course Review } \\
\text { Horay (CRH) } \\
\text { Terhadap Hasil } \\
\text { Belajar IPA Pada } \\
\text { Siswa Kelas V SD } \\
\text { Tahun Pelajaran } \\
\text { 2013/2014 di } \\
\text { Gugus IV } \\
\text { Kecamatan } \\
\text { Buleleng }\end{array}$ & $\begin{array}{l}\text { Ni Made Marteni } \\
\text { Dewi, Desak } \\
\text { Putu Parmiti, } \\
\text { Putu Nanci } \\
\text { Riastini }\end{array}$ & $\begin{array}{c}\text { Jurnal Mimbar } \\
\text { PGSD } \\
\text { Universitas } \\
\text { Pendidikan } \\
\text { Ganesha }\end{array}$ & 15,62 & 21,83 & 6,21 & 39 \\
\hline \multirow[t]{2}{*}{10} & $\begin{array}{l}\text { Pengaruh Model } \\
\text { Pembelajaran } \\
\text { Course Review } \\
\text { Horay Terhadap } \\
\text { Hasil Belajar IPS } \\
\text { Siswa Kelas V } \\
\text { SDN } 15 \text { Sungai } \\
\text { Geringging }\end{array}$ & Holisna Midola & $\begin{array}{c}\text { Jurnal Bung } \\
\text { Hatta }\end{array}$ & 73 & 82 & 9 & 12 \\
\hline & \multicolumn{3}{|c|}{ RATA-RATA } & 48,50 & 62,65 & 14,14 & 33,4 \\
\hline
\end{tabular}

Berdasarkan hasil serangkaian $(\mathrm{CRH})$ sangat efektif daripada model terdahulu. pengujian dalam Jurnal Iqra': Kajian Ilmu Berdasarkan hasil serangkaian Pendidikan yang diuji oleh Nur Eva dan Siska pengujian dalam Bitnet: Jurnal Pendidikan Wulandari pada siswa kelas V SD Negeri 5 Teknologi Informasi yang diuji oleh Ramli dan Merak Batin Lampung Selatan dapat Isnawati pada peserta didik kelas IV SDN 2 disimpulkan bahwa, hasil penelitian yang telah Ruwung Buyung Kecamatan Cempaga Hulu dilakukan memberikan hasil yang berbeda dapat disimpulkan bahwa, terjadi peningkatan terhadap hasil belajar IPS siswa yang memakai hasil belajar pada peserta didik kelas IV SDN 2 model pembelajaran $(C R H)$ dibanding tidak menggunakan model pembelajaran (CRH). Ruwang Buyung kecamatan Cempaga Hulu setelah menggunakan model pembelajaran Sesuai dengan kretria hasil penghitungan uji ttes Thit > 7,81 lebih besar dari 1,67 maka Ha diterima. Hasil belajar peserta didik di kelas yang diberi treatment lebih baik daripada di kelas kontrol. Artinya, keberhasilan proses pembelajaran dengan model pembelajaran coursey review horay, dan peningkatan hasil belajar peserta didik dapat dilihat dari hasil belajar pada siklus I sebanyak 46,42\% peserta didik yang tuntas dan pada siklus II sebanyak $89,28 \%$ peserta didik yang tuntas.

Berdasarkan hasil serangkaian 
pengujian dalam Journal Elementary Education yang diuji oleh Meidian Kusumahati pada peserta didik kelas V SD Negeri Mintaragen 1 dan 7 kota Tegal, dapat disimpulkan terdapat perbedaan hasil belajar IPS peserta didik kelas $\mathrm{V}$ antara yang menggunakan model pembelajaran kooperatif $\mathrm{CRH}$ dan yang menggunakan model terdahulu. Perhitungan penelitian ini menggunakan rumus independent samples $t$ test menunjukkan bahwa model pembelajaran kooperatif $\mathrm{CRH}$ berpengaruh secara optimal terhadap hasil belajar peserta didik. Model pembelajaran CRH memiliki efek yang baik untuk meningkatkan hasil belajar peserta didik kelas $\mathrm{V}$ pada mata pelajaran IPS yang telah dibuktikan dengan rata-rata nilai di kelas yang diberi treatment lebih baik daripada di kelas yang tidak diberi treatment. Di kelas yang tidak diberi treatment, rata-rata nilai hasil belajar peserta didik 68,55, sedangkan di kelas treatment 81,25.

Berdasarkan hasil serangkaian pengujian dalam Primary: Jurnal Keilmuan dan Kependidikan Dasar yang diuji oleh Siti Hamdah, Umayah pada peserta didik kelas IV MI Al-Falahiyyah Rajeg, dapat disimpulkan nilai rata-rata post-test dikelas yang diberi treatment sebesar 79,09, sedangkan di kelas yang tidak diberi treatment yaitu 67,27. Hasil uji statistik dengan menggunakan uji-t pada kelas yang diberi treatment dan kelas yang tidak diberi treatment yaitu 0 hasil, dari sini terlihat bahwa model (CRH) memiliki pengaruh yang optimal terhadap hasil belajar IPS materi perkembangan teknologi transportasi pada siswa kelas IV MI Al-Falahiyyah Rajeg. Berdasarkan hasil serangkaian pengujian dalam Jurnal Pemikiran dan Pengembangan Sekolah Dasar (JP2SD) yang diuji oleh Yulia Ratna Hesti Setyaningsih, Qoriati Mushafanah, Henry Januar Saputra pada peserta didik kelas VA SD Negeri 03 Kayen, dapat disimpulkan bahwa, hasil dalam penelitian ini diperoleh dari nilai pretest dan posstest serta observasi untuk aktivitas belajar. Hasil uji-t diperoleh thitung = 8,393 dengan ttabel $=2,086$ maka thitung > ttabel yang artinya model pembelajaran $(\mathrm{CRH})$ dapat memberi peningkatan hasil belajar siswa. Serta ada perbedaan hasil belajar siswa pretest dan posstest siswa dengan memakai model pembelajar $(C R H)$ dibuktikan dengan rata - rata gain diperoleh $45 \%$ yang berkategori "Sedang". Hasil dari ketuntasan klasikal yang awalnya hanya $40 \%$ menjadi $90 \%$.

Berdasarkan hasil serangkaian pengujian dalam Journal for Lesson and Learning Studies yang diuji oleh G.H. Andika Pratama, Ndara Tanggu Renda, Ketut Pudjawan pada peserta didik kelas V SD di Gugus II Kecamatan Tejakula, dapat disimpulkan bahwa, hasil penelitian diperoleh melalui metode tes instrumen pilihan ganda yang dianalaisis menggunakan teknik analisis statistik deskriptif dan statistik infrensial (uji-t). Hasil penelitian memaparkan bahwa ada pengaruh pada hasil belajar IPS antara kelompok siswa yang dibelajarkan memakai model pembelajaran (CRH) berbantuan media audio visual dan yang dibelajarkan tidak memakai model $(\mathrm{CRH})$, dengan nilai thitung $=2,384$ lebih besar dari 
$\operatorname{ttab}=1,980$. Artinya perbedaan dalam penerapan model pembelajaran dapat memengaruhi hasil belajar IPS siswa kelas V SD di Gugus II Kecamatan Tejakula semester genap tahun pelajaran 2017/2018.

Berdasarkan hasil serangkaian pengujian dalam Jurnal Basic Education yang diuji oleh Nurul Afifah Cholifatin pada peserta didik kelas IV SDN Sambungmacan 3, dapat disimpulkan, pada Pra-siklus nilai rata-rata ketuntasan $26,31 \%$. Pada siklus I nilai rata-rata ketuntasan mencapai 57,89\%. Pada siklus II nilai rata-rata ketuntasan mencapai $84,21 \%$, berdasarkan hasil tersebut penelitian dihentikan pada siklus II. Berdasarkan hasil penelitian penggunaan model pembelajaran Course Review Horay dapat meningkatkan hasil belajar IPS siswa kelas IV di SD/Negeri Sambungmacan 3, Kabupeten Sragen.

Berdasarkan hasil serangkaian pengujian dalam e-Journal PGSD Universitas Pendidikan Ganesha yang diuji oleh Ni Kadek Ani, Ni Nyoman Garminah, I Kadek Suartama pada peserta didik kelas IV SDN 4 Kalibukbuk Gugus XV Kecamatan Buleleng dapat ditarik kesimpulannya, rata-rata hasil belajar Matematika kelompok yang diberi treatment $(18,63)$ lebih besar dari rata-rata $(11,12)$ kelompok yang tidak diberi treatment. Sehingga model pembelajaran CRH berbantuan LKS berpengaruh terhadap hasil belajar matematika siswa kelas IV SDN 4 Kalibukbuk Gugus XV Kecamatan Buleleng Tahun Pelajaran 2015/2016.

Berdasarkan hasil serangkaian pengujian dalam International Journal of Elementary Education yang diuji oleh Ni Made Marteni Dewi, Desak Putu Parmiti, Putu Nanci Riastini pada peserta didik kelas kelas V SDN 1 Alasangker dan kelas V SDN 3 Alasangker Gugus IV Kecamatan Buleleng dapat disimpulkan bahwa. Hasil penelitian menunjukkan ada perbedaan yang terlihat berpengaruh pada hasil belajar IPA antara kelompok siswa yang mendapatkan treatment dan kelompok siswa yang mengikuti pembelajaran terdahulu. Rerata skor yang diperoleh dari hasil belajar IPA siswa yang belajar dengan model pembelajaran $\mathrm{CRH}$ $(21,83)$ lebih besar daripada rerata skor kelompok siswa dengan model pembelajaran terdahulu $(15,2)$.

Berdasarkan hasil serangkaian pengujian dalam dalam Jurnal Bung Hatta yang diuji oleh Holisna Midola pada peserta didik kelas V SDN 15 Sungai Geringging dapat disimpulkan bahwa, hasil penelitian di kelas eksperimen didapatkan rata-rata 82.00 dan kelas kontrol 73.00. Dilihat dari hasil analisis data yang telah dilakukan diperoleh thitung $>$ ttabel dimana 2,80>1,68 maka hipotesis diterima. Perolehan pada hasil penelitian ini dapat disimpulkan bahwa terdapat pengaruh model pembelajaran (CRH) terhadap hasil belajar IPS peserta didik. Disarankan kepada guru untuk menerapkan model Course Review Horay dalam proses pembelajaran.

Berdasarkan hasil analisis data dan penelitian yang relevan dan telah teruji oleh 10 jurnal di atas menekankan bahwa, model 
pembelajaran Course Review Horay (CRH) memiliki pengaruh terhadap hasil belajar siswa pada tingkat sekolah dasar. Rata-rata yang diperoleh terhadap hasil belajar mencapai $33,4 \%$ dengan kategori yang terendah $11 \%$, tertinggi $65 \%$ dan total ketuntasan hasil belajar rata-rata setelah menerapkan model pembelajaran Course Review Horay (CRH) adalah mencapai $62,65 \%$. Dapat dilihat dari hasil tiap penelitian masing-masing memperoleh hasil yang berbeda-beda tetapi pada tiap jurnal yang ditulis oleh peneliti samasama mendapatkan perbedaan, dari yang awalnya tidak menggunakan treatment/model pembelajaran, setelah menggunakan treatment/model pembelajaran peneliti mendapatkan hasil belajar yang optimal hingga menghasilkan sebuah keberhasilan dalam proses pembelajaran di sekolah tingkat dasar.

Penulis dapat menganalisis bahwa terjadi perubahan hasil belajar yang telah dilakukan para peneliti dikarenakan adanya faktor-faktor yang berpengaruhi seperti adanya model pembelajaran Course Review Horay $(C R H)$, kondisi dari faktor internal yang bersumber dari dalam peserta didik, serta kondisi dari faktor eksternal yang berasal dari luar diri peserta didik yaitu keluarga, sekolah dan masyarakat.Dengan adanya pengaruh yang optimal antara model pembelajaran Course Review Horay (CRH) terhadap hasil belajar siswa sekolah dasar dapat menjadikan siswa untuk lebih aktif (Siti Hamidah, 2018:12). Selain itu, pembelajaran dengan menggunakan model Course Review Horay (CRH) dapat melatih pengetahuan dan pemahaman materi yang diajarkan serta memberikan semangat ketika proses pembelajaran berlangsung.

\section{Kesimpulan dan Saran}

Berdasarkan hasil analisis data dan penelitian yang relevan dan telah tersaji di atas menekankan bahwa, model pembelajaran $(\mathrm{CRH})$ berpengaruh terhadap hasil belajar siswa pada tingkat sekolah dasar. Rata-rata yang diperoleh terhadap hasil belajar mencapai $33,4 \%$ dengan kategori yang terendah $11 \%$, tertinggi $65 \%$ dan total ketuntasan hasil belajar rata-rata setelah menerapkan model pembelajaran $(C R H)$ mencapai $62,65 \%$. Dapat dilihat dari hasil tiap penelitian masing-masing memperoleh hasil yang berbeda-beda tetapi pada tiap jurnal yang ditulis oleh peneliti samasama mendapatkan perbedaan, dari yang awalnya tidak menggunakan treatment/model pembelajaran, setelah menggunakan treatment/model pembelajaran peneliti mendapatkan hasil belajar yang optimal hingga menghasilkan sebuah keberhasilan dalam proses pembelajaran di sekolah tingkat dasar.

Penulis dapat menganalisis bahwa terjadi perubahan hasil belajar yang telah dilakukan para peneliti dikarenakan adanya faktor-faktor yang berpengaruhi seperti adanya model pembelajaran Course Review Horay (CRH), kondisi dari faktor internal yang bersumber dari dalam peserta didik, serta kondisi dari faktor eksternal yang berasal dari luar diri peserta didik yaitu keluarga, sekolah 
dan masyarakat.

Dengan adanya pengaruh yang optimal antara model pembelajaran Course Review Horay (CRH) terhadap hasil belajar siswa sekolah dasar dapat menjadikan siswa untuk lebih aktif (Siti Hamidah, 2018:12). Selain itu, pembelajaran dengan menggunakan model Course Review Horay (CRH) dapat melatih pengetahuan dan pemahaman materi yang diajarkan serta memberikan semangat ketika proses pembelajaran berlangsung.

Saran yang penulis harapkan dari penelitian ini yaitu,

1. Bagi Guru; Diharapkan untuk guru yang menerapkan model Course Review Horay $(\mathrm{CRH})$ dapat memahami betul terkait sintaks model pembelajaran ini, sehingga kegiatan pembelajaran menjadi lebih menarik, menyenangkan serta bermakna dan mendapatkan hasil belajar yang optimal bagi peserta didik di jenjang sekolah dasar.

2. Bagi Peserta Didik; Diharapkan kepada peserta didik jejang SD, agar mengikuti proses pembelajaran dengan baik dan aktif sehingga tujuan pembelajaran dapat tercapai.

3. Bagi Peneliti Lain; Diharapkan untuk meneliti lebih lanjut tentang model pembelajaran $\mathrm{CRH}$, dalam bidang semua Ilmu Pendidikan supaya lebih memperhatikan dampak yang akan terjadi ketika penelitian ini digunakan sebagai bahan pertimbangan untuk penyempurnaan penelitian berikutnya.

\section{Daftar Pustaka}

\section{Dari Buku}

Huda, M. (2013). Model-Model Pengajaran dan Pembelajaran. Yogyakarta: Pustaka Pelajar.

Sani, I. K. (2015). Ragam Pengembangan

Model Pembelajaran: Untuk

Peningkatan Profesionalitas Guru. Jakarta: Kata Pena.

Shoimin, A. (2014). 68 Model Pembelajaran INOVATIF dalam Kurikulum 2013. Yogyakarta: AR-RUZZ MEDIA.

Sinar. (2018). Metode Active Learning. Yogyakarta: CV Budi Utama.

Sugiyono. (2019). Metode Penelitian

Pendidikan (Kuantitatif, Kualitatif, Kombinasi, R\&D dan Penelitian

Pendidikan. Bandung: Alfabeta.

Suprihatiningrum, J. (2013). STRATEGI

PEMBELAJARAN: Teori \&

Aplikasi. Yogyakarta: AR-RUZZ MEDIA.

Susanto, A. (2013). Teori Belajar dan

Pembelajaran di Sekolah Dasar. Jakarta: PRENADAMEDIA GROUP.

\section{Dari Jurnal}

Ani, G. S. (2016). Pengaruh Model

Pembelajaran CRH Berbantuan LKS Terhadap Hasil Belajar Matematika Siswa Kelas IV SD. Jurnal Mimbar PGSD Universitas Pendidikan Ganesha, Vol 4 (1) . Diakses pada tanggal 8 Agustus 2020. Dari https://ejournal.undiksha.ac.id/index. php/JJPGSD/article/view/7331.

Cholifatin, N. A. (2018). Meningkatkan Hasil Belajar IPS Dengan Model Course Review Horay Siswa Kelas IV. Basic Education, Vol 7 (30) halaman 3. Diakses pada tanggal 26 Juli 2020. Dari https://ejournal.undiksha.ac.id/index. 
php/IJEE/article/view/17281/10373.

Dewi, P. R. (2014). Pengaruh Model

Pembelajaran Kooperatif Tipe

Course Review Horay (CRH)

Terhadap Hasil Belajar IPA Pada

Siswa Kelas V SD Tahun Pelajaran

2013/2014 Di Gugus IV Kecamatan

Buleleng. Jurnal Mimbar PGSD

Universitas Pendidikan Ganesha, Vol

2 (1) halaman 2 . Diakses pada tanggal 8 Agustus 2020. Dari

https://ejournal.undiksha.ac.id/index. php/JJPGSD/article/view/2286.

G.H. Andika Pratama, N. T. (2018). Pengaruh Model Pembelajaran CRH

Berbantuan Media Audio Visual Terhadap Hasil Belajar IPS. Journal for Lesson and Learning Studies, Vol. 1 (1) halaman 2. Diakses pada tanggal 17 Juli 2020. Dari https://ejournal.undiksha.ac.id/index. php/JLLS/article/view/14628/8939.

Kusumahati, M. (2014). Keefektifan Model Course Review Horay Terhadap Peningkatan Hasil Belajar IPS. Journal Elementary Education, Vol 3 (2) halaman2 . Diakses pada tanggal 18 Juni 2020. Dari https://journal.unnes.ac.id/sju/index.p hp/jee/article/view/3691.

Midola, H. (2017). Pengaruh Model

Pembelajaran Course Review Horay Terhadap Hasil Belajar IPS Siswa Kelas V SDN 15 Sungai Geringging. Jurnal Bung Hatta, Vol 8 (1)

halaman 2 . Diakses pada tanggal 11 Agustus 2020. Dari

https://ejurnal.bunghatta.ac.id/?journ al $=$ JFKIP\&page $=$ article $\&$ op $=$ view $\&$ path\%5B\%5D=10572\&path\%5B\%5
$\mathrm{D}=8830$.

Nureva, S. W. (2019). Pengaruh Model

Pembelajaran Course Review Horay (CRH) Terhadap Hasil. Jurnal Iqra': Kajian Ilmu Pendidikan, Vol 4 (1) halaman 3 . Diakses pada tanggal 11 Juni 2020. Dari https://www.journal.iaimnumetrolam pung.ac.id/index.php/ji/article/view/4 80/381.

Ramli, I. (2016). Upaya Meningkatkan Hasil Belajar IPS Dengan Menggunakan Model Pembelajaran Course Revie Horay. Bitnet: Jurnal Pendidikan Teknologi Informasi, Vol 1 (1) halaman 2 . Diakses pada tanggal 16 Juni 2020. Dari

http://journal.umpalangkaraya.ac.id/i ndex.php/bitnet/article/view/763/712.

Setyaningsih, M. S. (2019). Pengaruh Model Pembelajaran Course Review Horay Untuk Meningkatkan Aktivitas dan Hasil Belajar Siswa Kelas V Sekolah Dasar. Jurnal Pemikiran dan Pengembangan Sekolah Dasar (JP2SD), Vol 7 (2) halaman 8 . Diakses pada tanggal 5 Juli 2020. Dari http://202.52.52.22/index.php/jp2sd/a rticle/view/8822/pdf.

Siti Hamidah, U. (2018). Pengaruh Model Course Review Horay Terhadap Hasil Belajar IPS Materi Mengenal Perkembangan Teknologi Transportasi. Primary: Jurnal Keilmuan dan Kependidikan Dasar, Vol 10 (01) halaman 12 . Diakses pada tanggal 29 Juni 2020. Dari http://jurnal.uinbanten.ac.id/index.ph p/primary/article/view/1256/974. 